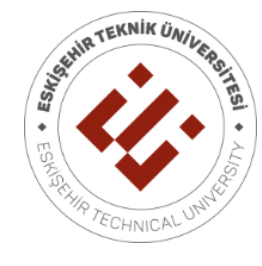

ESKISSEHIR TECHNICAL UNIVERSITY JOURNAL OF SCIENCE AND TECHNOLOGY A- APPLIED SCIENCES AND ENGINEERING

2019, Vol: 20, pp. 24 - 29, DOI: 10.18038/estubtda.630211

\title{
GREEN REDUCTION OF GRAPHENE OXIDE BY USING KOMBUCHA TEA
}

\author{
Nurşah KÜTÜK ${ }^{1}$, Filiz BORAN², Sevil ÇETINKAYA GÜRER ${ }^{1, *}$ \\ ${ }^{1}$ Sivas Cumhuriyet University, Department of Chemical Engineering, 58140, Sivas / Turkey \\ ${ }^{2}$ Hitit University, Department of Chemical Engineering, Çorum / Turkey
}

\begin{abstract}
In this study, a simple and efficient method of reduction for the preparation of reduced graphene oxide (RGO) from graphene oxide (GO) using Kombucha Tea (KT) is reported. The graphene oxides (GOs) were produced from natural graphite (Gr) powders based on Hummers' method. KT was used as natural reductants to reduction of GO. Polyphenol content of KT was determined by using Folin-Cioceltau method. KT and GO were mixed in certain ratios to reduce graphene oxide (RGO) at room temperature. RGO was characterized by X-Ray Diffraction (XRD), Scanning Electron Microscopy (SEM) and Fourer Transform Infrared (FTIR). It was clearly observed that the functional groups containing oxygen were reduced as a result of the analyzes.
\end{abstract}

Keywords: Graphene Oxide, Kopmbucha Tea, Reduction, Graphite Powder

\section{INTRODUCTION}

Graphene is one of the most important materials in the universe because of its excellent electrical, mechanical and thermal properties. Graphene and its derivatives have attracted the attention of researchers in the recent years because of their use in many fields including biological, biomedical, electrochemical energy storage devices, electrochemical sensors [1,2]. RGO is the most important material among the chemically modified graphene since its structure and properties are close to primitive graphene. Many researchers have focused on synthesis and application of graphene due to its excellent electrical, mechanical and thermal properties [3,4]. Some methods are used to prepare RGO such as hydrothermal dehydration [5], solvothermal reduction [6], catalytic and chemical reductions [2]. Chemical reduction of GO is one of the most widely used conventional methods. These methods for reducing graphene oxide are toxic to the ecosystem. The toxicity of the chemical agents used in the reduction process such as hydrazine, sodium borohydride is a disadvantage in the use of the material in bio-applications. The green reduction is proposed to be a convenient and safe alternative candidate to conventional methods since it is cost effective and less toxic way for reducing of graphene oxide [7]. Various green reagents such as Lycium Barbarum and Cinnamon extracts have been used on reduction of GO $[8,9]$. Chrysanthemum extract which is a natural and harmless reductant has been used for the preparation of reduced GO [10]. This promising approach in the preparation of various graphene-based materials, especially for biomaterials, is a pioneer and foundation for green method applications. GO and RGO have been also used in biomedical applications. Bacterially RGO was investigated on the inhibition of cell viability, reactive oxygen species generation, and membrane integrity in human breast cancer cells. In the research, a green and a simple approach to produce graphene using bacterial biomass as a reducing and stabilizing agent was developed [11]. Although various green reagents have been used in some studies to reduce of GO, no studies have been found using Kombucha Tea as a reducing agent.

In the present study, a green and facile method conducted with a simple procedure using KT as the reductant was employed in the chemical reduction of GO. The characterization results show that GO is reduced.

*Corresponding Author: cetinkaya.sevil@gmail.com

Received: 26.09.2019 Published: 16.12.2019 


\section{MATERIALS AND METHOD}

\subsection{Experimental}

\subsubsection{Raw materials}

The powder graphite (C) and Sulfuric Acid $\left(\mathrm{H}_{2} \mathrm{SO}_{4}, 98 \%\right)$ used in the study were obtained from SigmaAldrich. Sodium Nitrate $\left(\mathrm{NaNO}_{3}\right)$ and Hydrochloric Acid $(\mathrm{HCl}, 37 \%)$ were purchased from Merck. Potassium Permanganate $\left(\mathrm{KMnO}_{4}\right)$ was obtained from Aklar Chemicals and Hydrogen Peroxide $\left(\mathrm{H}_{2} \mathrm{O}_{2}\right.$, $30 \%$ ) was obtained from Tekkim. Folin-Cioceltau reagent was obtained from Carlo Erba, Gallic Acid $\left(\mathrm{C}_{7} \mathrm{H}_{6} \mathrm{O}_{5}\right)$, Sodium Carbonate $\left(\mathrm{Na}_{2} \mathrm{CO}_{3}\right)$ Sigma-Aldrich and Ethanol $\left(\mathrm{C}_{2} \mathrm{H}_{5} \mathrm{OH}\right)$ were procured from Tekkim for the determination of total phenolic content of the extract.

\subsubsection{Preparation of Kombucha Tea and Folin Cioceltau Method}

The Folin-Ciocalteu (F- C) reaction is an antioxidant assay based on electron transfer, which measures the reductive capacity of an antioxidant. It has been widely applied in determination of the total phenol/polyphenol content of plant- derived food and biological samples [12]. Traditional preparation of KT is easy. After $3 \mathrm{~L}$ of water is boiled, 250 grams of sugar is added on it. Then, black tea is added on the mixture and after waiting $10 \mathrm{~min}$ brewed medium is ready. Kombucha mushroom is released into the medium. Thus, fermentation is started. The KT was used to reduce GO after fermentation period of 8 days. As the acidity of KT increases with the fermentation time, 8 th day fermentation tea was used in the study. Folin-Ciocalteu method was used to determine the content of total polyphenols in KT by the UV/Vis spectrophotometric method. Folin reagent was added to KT in alkaline medium. The absorbance of this solution was measured at $765 \mathrm{~nm}$ (Fig.1.). The amount of Gallic Acid is equivalent to the total amount of phenolic acid. Therefore, the Gallic Acid calibration graph was prepared by measuring the absorbance at $765 \mathrm{~nm}$ by UV spectroscopy. The phenolic content of KT was calculated as $74.19 \mathrm{mg} /$ $\mathrm{ml}$ on the 8th fermentation day (Figure 1).

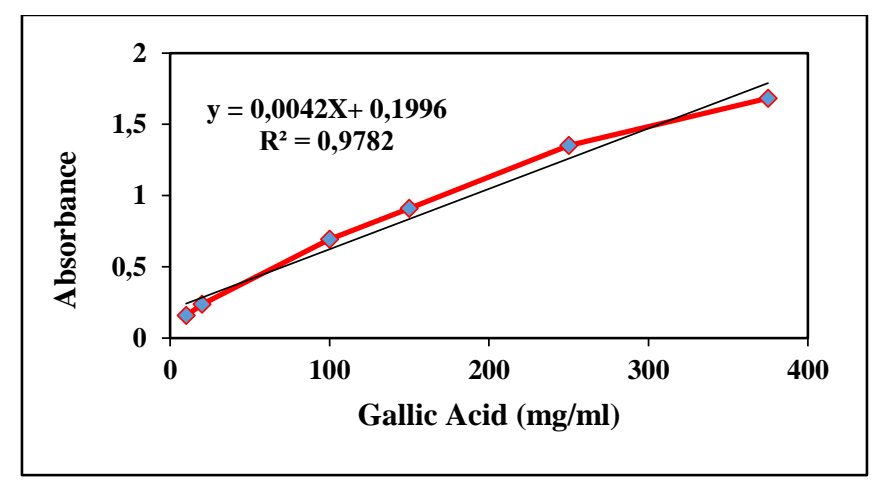

Figure 1. The calibration curve made with Gallic acid for Folin-Ciocalteu method in alcoholic medium

\subsubsection{Preparation of GO and RGO}

GO was successfully prepared by natural graphite (Gr) by a modified Hummer's method [13]. The synthesized GO was reduced by using KT. $50 \mathrm{mg}$ of GO sample and $100 \mathrm{~mL}$ of extract of KT were stirred in the magnetic stirrer for 1 hour at room temperature. The resulting suspension was precipitated by centrifugation at $2000 \mathrm{rpm}$. RGO was produced by drying this black-brown precipitate in an oven at $60{ }^{\circ} \mathrm{C}$ for 24 hours. 


\section{RESULT AND DISCUSSION}

\subsection{XRD}

The XRD patterns of GO and RGO reduced by KT and Gr are shown in Fig. 2. The Gr usually has a sharp and well-defined peak at $2 \theta=26.36^{\circ}$ in consistent with a d-spacing of $0.34 \mathrm{~nm}$. The relatively broader d-spacing of GO $\left(0.73 \mathrm{~nm}, 2 \theta=12.1^{\circ}\right)$ than that of $\mathrm{Gr}$ is due to the intercalation of water molecules and the formation of oxygen-containing functional groups between the layers during the oxidation of graphite, such as epoxy, hydroxyl, carboxyl and carbonyl groups [14]. After reduction of $\mathrm{GO}$, the characteristic peak of $\mathrm{GO}$ at $2 \theta=12.1^{\circ}$ has disappeared in the diffraction pattern of RGO indicating the absolute exfoliation of the GO [9]. It is seen that peak of Gr at $2 \theta=26.36^{\circ}$ also disappeared in the diffraction pattern of GO and RGO (Fig.2.).

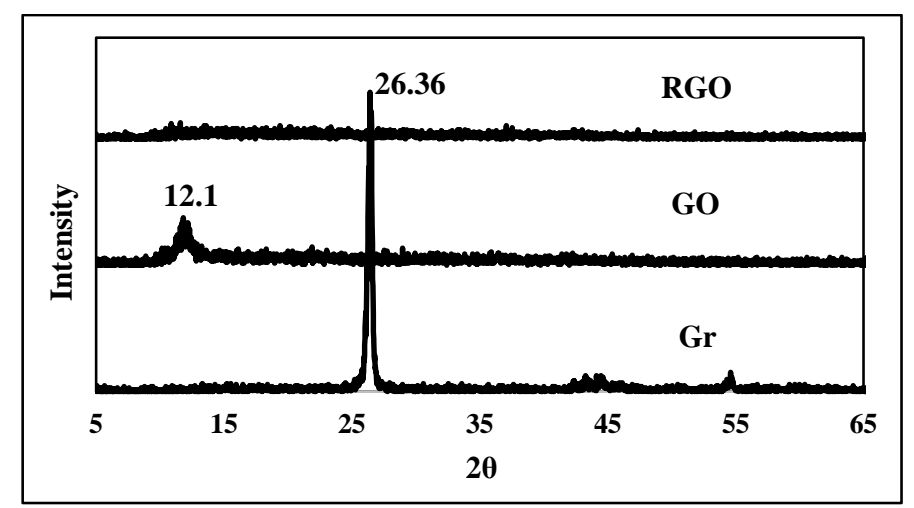

Figure 2. XRD patterns of RGO reduced by $\mathrm{KT}, \mathrm{GO}$ and $\mathrm{Gr}$

\subsection{FITR}

Figure 3 shows the FTIR spectra of Gr, GO and RGO. The GO spectrum as seen in Fig. 3 shows the peak at $1039 \mathrm{~cm}^{-1}$ is attributed as C-O stretching. The peak at $3236 \mathrm{~cm}^{-1}$ is confirmed as O-H stretching vibration of the $\mathrm{C}-\mathrm{OH}$ groups and water content in the material. The carbonyl groups are also shown at $1715 \mathrm{~cm}^{-1}$ as $\mathrm{C}=\mathrm{O}$ stretching, the peak at $1617 \mathrm{~cm}^{-1}$ is attributed as aromatic carbon band $(\mathrm{C}=\mathrm{C})$. The peak at $1357 \mathrm{~cm}^{-1}$ is confirmed as $\mathrm{C}-\mathrm{O}$ epoxy band [15]. FTIR spectroscopy indicated the existence of $-\mathrm{OH}\left(\sim 3236 \mathrm{~cm}^{-1}\right), \mathrm{C}=\mathrm{O}\left(1715 \mathrm{~cm}^{-1}\right)$, and $\mathrm{C}=\mathrm{C}\left(1617 \mathrm{~cm}^{-1}\right)$ functional groups in the $\mathrm{GO}$ which is confirmed the synthesis of GO from graphite [16]. It is seen from the Fig. 3 that the FTIR spectrum of RGO structure is similar to GO structure. The decrease of peaks at 1715, 1617, 1357 and $1039 \mathrm{~cm}^{-1}$ in RGO is indication of removal of the oxygen functional group in GO [ 17]. 


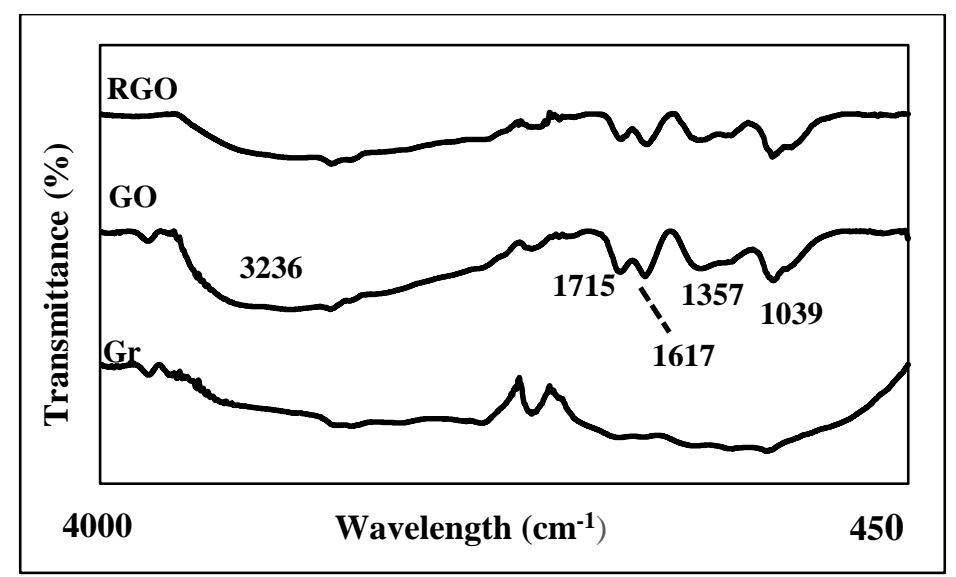

Figure 3. FTIR spectrum of RGO reduced by KT, GO and Gr

\subsection{SEM}

Figure 4 indicates the SEM images of Gr and GO. Graphite morphology seems to be compact heaps with well-defined edges due to the Van der Waals forces that hold the layers together. As seen from Fig. 4(b), GO nanosheets with a layered structure has highly wrinkled surface textures [18].

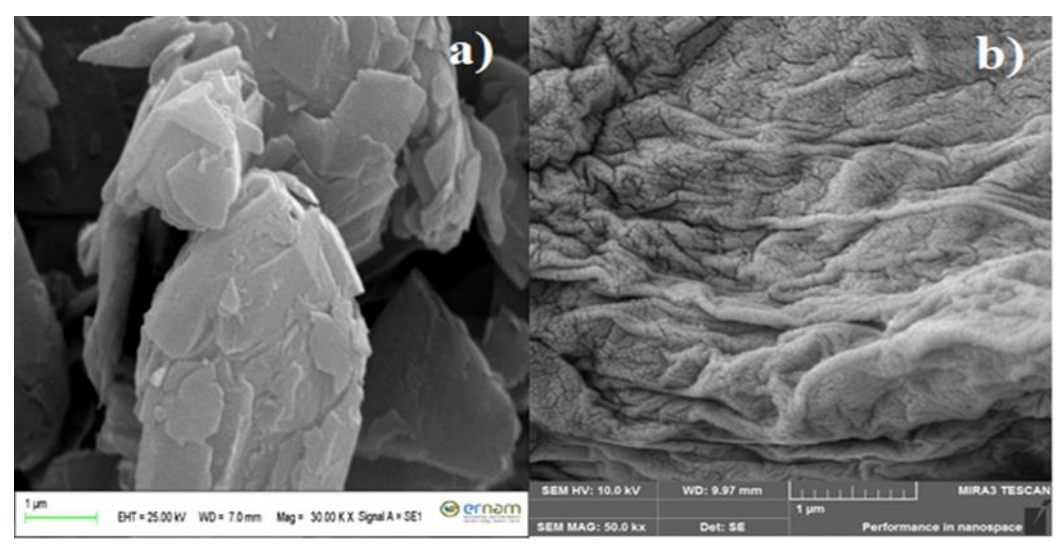

Figure 4. SEM images of Gr (a) and GO (b)

\section{CONCLUSION}

We have demonstrated a green, an ecofriendly and facile approach for the reduction of GO by using Kombucha Tea. GO and RGO reduced by KT were characterized by using FTIR, XRD and SEM techniques. These techniques confirmed that RGO was obtained from GO using KT. Therefore, it can be say that KT is a potential substitute for the large-scale production of graphene.

\section{ACKNOWLEDGEMENTS}

This study was supported by Sivas Cumhuriyet University Scientific Research Projects (CÜBAP), project number as M702. 


\section{REFERENCES}

[1] Puangjan A, Chaiyasith S. An efficient $\mathrm{ZrO} 2 / \mathrm{Co} 3 \mathrm{O} 4 /$ reduced graphene oxide nanocomposite electrochemical sensor for simultaneous determination of gallic acid, caffeic acid and protocatechuic acid natural antioxidants. Electrochimica Acta 2016; 211: 273-288.

[2] Joung D, Singh V, Park S, Schulte A, Seal S, Khondaker SI. Anchoring Ceria Nanoparticles on Reduced Graphene Oxide and Their Electronic Transport Properties. |J. Phys. Chem C 2011; 115: 24494-24500.

[3] Ban FY, Majid SR, Huang2 NM, Lim HN. Graphene Oxide and Its Electrochemical Performance. Int. J. Electrochem. Sci 2012; 7: 4345 - 4351.

[4] Zhu L, Zhao Z, Li Y, Yu X, Li C, Zhang Q. High-quality production of graphene by liquid-phase exfoliation of expanded graphite. Materials Chemistry and Physics 2013; 137: 894-990.

[5] Alazmi A, Rasul S, Patole SP, Costa PM.F.J. Comparative study of synthesis and reduction methods for graphene oxide. Polyhedron 2016; 116: 153-161.

[6] Zhu L, Zhao X, Li Y, Yu X, Li C, Zhang Q. High-quality production of graphene by liquid-phase exfoliation of expanded graphite. Materials Chemistry and Physics 2013;3 137 (2013): 984- 990.

[7] Thakur S, Karak N. Alternative methods and nature-based reagents for the reduction of graphene oxide: A review. Carbon 2015; 94: 224-242.

[8] Hou D, Liu Q, Cheng H, Zhang H, Wang S. Green reduction of graphene oxide via Lycium barbarum extract. Journal of Solid State Chemistry 2017; 246: 351-356.

[9] Suresh D, Udayabhanu, Kumar M.A.P, Nagabhushana H, Sharma SC. Cinnamon supported facile green reduction of graphene oxide, its dye elimination and antioxidant activities. Materials Letters 2015; 151: 93-95.

[10] Hou D, Liu Q, Cheng H, Li K, Wang D, Zhang H. Chrysanthemum extract assisted green reduction of graphene oxide. Materials Chemistry and Physics 2016;183: 76-82.

[11] Gurunathan S, Han JW, Eppakayala V, Kim JH. Green synthesis of graphene and its cytotoxic effects in human breast cancer cells. International Journal of Nanomedicine 2013; $8: 1015-1027$.

[12] Noreen H, Semmar N, Farman M, McCullagh JSO. Measurement of total phenolic content and antioxidant activity of aerial parts of medicinal plant Coronopus didymus. Asian Pacific Journal of Tropical Medicine 2017; 10(8): 792-801.

[13] Guo J, Zhu S, Chen Z, Li Y, Yu Z, Liu Q, Li J, Feng C, Zhang D. Sonochemical synthesis of TiO2 nanoparticles on graphene for use as photocatalyst. Ultrasonics Sonochemistry 2011; 18: 10821090.

[14] Hou D, Liu Q, Wang X, Quan Y, Qiao Z, Yu Li, Ding S. Facile synthesis of graphene via reduction of graphene oxide by artemisinin in ethanol. Journal of Materiomics 2018; $4: 256-265$. 
[15] Andrijanto E, Shoelarta S, Subiyanto G, Rifki S. Facile Synthesis of Graphene from Graphite Using Ascorbic Acid as Reducing Agent, The 3rd International Conference on Advanced Materials Science and Technology (ICAMST 2015)

[16] Rahmanian N, Hamishehkar H, Dolatabadi JE, Arrsalani N. Nano graphene oxide: A novel carrier for oral delivery of flavonoids, Colloids and Surfaces B: Biointerfaces 2014, 123, 331-338.

[17] Tiyek İ, Dönmez U, Yıldırım B, Alma MA, Ersoy M, Karataş SŞ, Yazıcı M. Kimyasal yöntem ile indirgenmiş grafen oksit sentezi ve karakterizasyonu, SAÜ Fen Bilimleri Dergisi; 2016, 20, 349357.

[18] Romero A, Lavin-Lopez MP, Sanchez-Silva L, Valverde JL, Paton-Carrero A. (2018). Comparative study of different scalable routes to synthesize graphene oxide and reduced graphene oxide, Materials Chemistry and Physics 203, 284-292. 